\title{
Intraseasonal response of the northern Indian Ocean coastal waveguide to the Madden-Julian Oscillation
}

\author{
J. Vialard, ${ }^{1}$ S. S. C. Shenoi, ${ }^{2}$ J. P. McCreary, ${ }^{3}$ D. Shankar, ${ }^{4}$ F. Durand, ${ }^{5}$ V. Fernando, ${ }^{4}$ \\ and S. R. Shetye ${ }^{4}$
}

Received 1 April 2009; revised 26 May 2009; accepted 15 June 2009; published 21 July 2009

[1] A new observational record of upper-ocean currents at $15^{\circ} \mathrm{N}$ on the western coast of India is dominated by intraseasonal (55-110 day) variations of alongshore currents, whereas sea level at the same location has a clear seasonal signal. These observations can be interpreted within the framework of linear wave theory. At $15^{\circ} \mathrm{N}$, the minimum period for planetary waves is $\sim 90$ day, meaning that intraseasonal energy is largely trapped at the coast in the form of poleward-propagating Kelvin waves, while lower-frequency signals associated with the annual cycle can radiate offshore as planetary waves. This dynamical difference results in a steeper offshore slope of sea level at intraseasonal timescale, and thus stronger geostrophic alongshore currents. A consequence is that the alongshore currents are in-phase with intraseasonally-filtered sea level near the coast, and a gridded satellite product is shown to reproduce the current variations reasonably well. The intraseasonal current variations along the west coast of India are part of basin-scale sea-level fluctuations of the Northern Indian Ocean equatorial and coastal waveguides. The wind forcing associated with this basin scale circulation closely matches surface wind signals associated with the MaddenJulian Oscillation. Citation: Vialard, J., S. S. C. Shenoi, J. P. McCreary, D. Shankar, F. Durand, V. Fernando, and S. R. Shetye (2009), Intraseasonal response of the northern Indian Ocean coastal waveguide to the Madden-Julian Oscillation, Geophys. Res. Lett., 36, L14606, doi:10.1029/2009GL038450.

\section{Introduction}

[2] The variability of winds north of $10^{\circ} \mathrm{S}$ in the Indian Ocean is dominated by the annual cycle. The alternating southwest/northeast monsoons provide a strong annual and semi-annual forcing that drives a basin-scale sea-level response involving both equatorial wave dynamics and coastal wave propagation around the perimeter of the northern Indian Ocean [McCreary et al., 1993]. The East India Coastal Current, for example, is strongly influenced by remote wind forcing from the equatorial region (through

\footnotetext{
${ }^{1}$ Laboratoire d'Océanographie Expérimentation et Approches Numériques, IRD, Université Pierre et Marie Curie, Paris, France.

${ }^{2}$ Indian National Centre for Ocean Information Services, Hyderabad, India.

${ }^{3}$ International Pacific Research Centre, University of Hawaii, Honolulu, Hawaii, USA.

${ }^{4}$ Physical Oceanography Division, National Institute of Oceanography, CSIR, Goa, India.

${ }^{5}$ Laboratoire d'Etudes en Géophysique et Oceanographie Spatiales, IRD, Toulouse, France.
}

Copyright 2009 by the American Geophysical Union. 0094-8276/09/2009GL038450 the equatorial and coastal waveguides) and from the interior of the Bay of Bengal (through planetary waves) [McCreary et al., 1996]. Coastal Kelvin waves then travel around Sri Lanka and the southern tip of India to impact the West India Coastal Current (WICC) [McCreary et al., 1993; Shankar and Shetye, 1997].

[3] The Indian Ocean is also home to significant intraseasonal variability (see, e.g., Goswami [2005] for a review). In particular, the Madden-Julian Oscillation (hereafter MJO) [Zhang, 2005] has energetic fluctuations of deep atmospheric convection and surface winds in the 30-80 day range [Wheeler and Hendon, 2004]. In summer the MJO is associated with active and break phases of the southwest monsoon, while in winter it shifts to the southern hemisphere. The MJO, however, has a wind signature in the equatorial band all year long.

[4] This intraseasonal wind variability drives a significant surface current response in the equatorial waveguide [e.g., Reppin et al., 1999; Senan et al., 2003; Masumoto et al., 2005; Han et al., 2001; Sengupta et al., 2007]. While equatorial intraseasonal variability of currents and sea level has been addressed in several studies, studies focusing on the northern Indian Ocean are scarce. Sengupta et al. [2001] concluded that current fluctuations south of Sri Lanka are largely driven by instabilities phase locked to the intraseasonal wind forcing. Durand et al. [2009] used alongtrack satellite data to describe the variability of currents and sea level along the east coast of India, finding significant intraseasonal variability superimposed on the seasonal cycle. Shetye et al. [2008] found that remote forcing makes a significant contribution to the variability of observed currents at $15^{\circ} \mathrm{N}$ on the west coast of India at periods longer than 10 days.

[5] In this paper, we describe intraseasonal current and sea-level variations in the coastal waveguide of the northern Indian Ocean, with emphasis on the forcing that drives them. Toward that end, we use a combination of satellite observations (sea level and wind stress), as well as a newly acquired current dataset off Goa, at $15^{\circ} \mathrm{N}$ on the west coast of India (see Figure 1a for location). The latter dataset is dominated by intraseasonal fluctuations of the alongshore current, a feature that can be explained by linear wave theory. The current variations are part of basin-scale sealevel fluctuations of the Northern Indian Ocean equatorial and coastal waveguides in response to intraseasonal winds associated with the MJO.

\section{Data}

[6] We use the weekly high resolution $\left(0.25^{\circ}\right)$, merged, mapped, delayed-time, sea-level product produced by CLS 


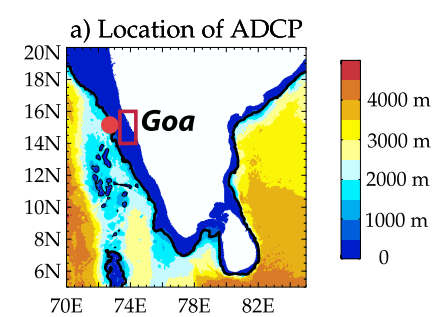

b) alongshore current and intraseasonal sea level
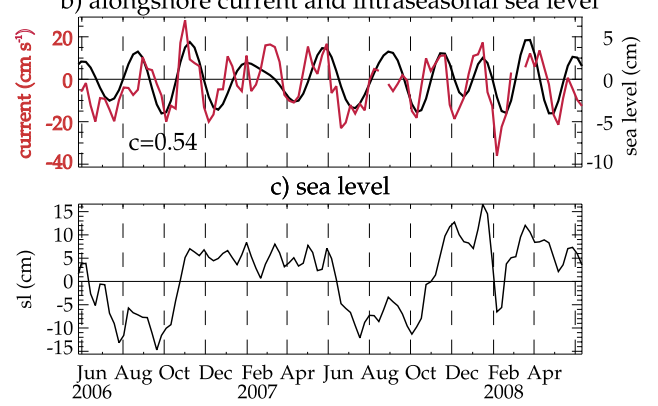

Figure 1. (a) Map of peninsular India and bathymetry (with $1000 \mathrm{~m}$ contour in black). A red circle indicates the location of the ADCP on the shelf break off the state of Goa, on the western Coast of India. The red box $\left(73^{\circ} \mathrm{E}\right.$ to $74^{\circ} \mathrm{E}$, $14^{\circ} \mathrm{N}$ to $16^{\circ} \mathrm{N}$ ) indicates the averaging region for sea level plotted in Figures 1b and 1c. (b) Weekly alongshore current at 50m measured by the ADCP (red curve) and 55-110 day filtered sea level. (c) Sea level.

(Collecte Localisation Satellite) in the framework of the DUACS project (available from http://www.jason.oceanobs. com $/ \mathrm{html} /$ donnees/duacs/access_fr.html). This product was available from 14 October $199 \overline{2}$ until 11 June 2008 at the time of writing.

[7] We use wind stress determined from the ERS $\left(1^{\circ}\right.$ and weekly resolution) and QuikSCAT $\left(0.5^{\circ}\right.$ and daily resolution) scatterometers obtained from http://www.ifremer.fr/ cersat/en/data/download/download.htm. Daily anomalies with respect to each product climatology were combined with a smooth transition between the two products to form a daily record on a $0.5^{\circ}$ grid during 5 March 1992 to 28 January 2009.

[8] An upward-looking RDI $75 \mathrm{kHz}$ Long-Ranger Acoustic Doppler Current Profiler (ADCP) was deployed in $1145 \mathrm{~m}$ of water on a subsurface mooring at $15^{\circ} 09^{\prime} \mathrm{N}$ $72^{\circ} 43^{\prime} \mathrm{E}$ on the continental slope off Goa (see Figure 1a). The dataset is 838 days long (from 26 May 2006 to 16 September 2008). The ADCP sampled in high-resolution mode, recording ensemble pressure and velocity in 8-m bins at depths above the nominal ADCP location at $400 \mathrm{~m}$. The accuracy of the velocity measurements is better than $1.8 \mathrm{~cm} \mathrm{~s}^{-1}$. In this paper, we use the alongshore component of the velocity from the bin centered around $50 \mathrm{~m}$. For comparison with weekly sea-level data, the hourly current values were averaged over a week, and restricted to the period of available sea-level data (i.e., until 11 June 2008).

\section{Results}

[9] The ADCP mooring provides the first long current record (24 months; Figure 1a) that resolves intraseasonal variability on the west coast of India. Previous descriptions of the WICC obtained from hydrography, ship drift and satellite-tracked drifters suggested a seasonal reversal with $20 \mathrm{~cm} \cdot \mathrm{s}^{-1}$ peak-to-peak amplitude, with a southward (northward) current during the southwest monsoon (JanuaryFebruary) [Shenoi et al., 1999; Schott and McCreary, 2001, and references therein]. The mooring alongshore current shows no clear seasonal cycle; rather, it exhibits strong intraseasonal variability with a peak-to-peak amplitude of $40 \mathrm{~cm} \mathrm{~s}^{-1}$ (Figure 1b). Spectral analysis shows a sharp peak of variance between 55 and 110 days (Figure 2a). In the rest of the paper, we filter in that frequency band (55-110 day) to isolate signals associated with this variability. We note that our results are robust when a different intraseasonal filtering (e.g., 30-120 day) is used (not shown).

[10] In contrast to currents, sea-level variations on the shelf display a clear seasonal cycle (Figure 1c), with an abrupt sea-level rise in October-November and fall in June-July, coinciding with the arrival of the seasonal downwelling and upwelling coastal Kelvin waves [Shankar and Shetye, 1997]. On the other hand, the intraseasonal component of the sea level (55-110 day band-passed anomaly with respect to the mean seasonal cycle, Figure $1 b$ ) is roughly able to capture the current variations on the slope (correlation of 0.54 significant at $95 \%$ ).

[11] Why do intraseasonal sea level and alongshorecurrent variations tend to be in phase, and why is the seasonal cycle of currents so weak? This observation can be explained within the framework of linear wave theory. At a particular latitude $y$ there is a critical period, $P_{c r}=4 \pi y / c_{1}$, where $c_{1}$ is the speed of a first-baroclinic-mode Kelvin wave. Coastal signals with periods $P>P_{c r}$ radiate offshore as Rossby waves, whereas signals with $P<P_{c r}$ remain coastally trapped as coastal Kelvin waves. A typical value of $c_{1}$ along the west coast of India is $2.6 \mathrm{~m} \mathrm{~s}^{-1}$ [Chelton et al., 1998], so that $P_{c r}=92$ days at $y=15^{\circ} \mathrm{N}$. Higher-order baroclinic modes have different (larger) values of $P_{c r}$.

[12] At the mooring site, then, a significant portion of the intraseasonal (55-110 day) sea-level variations have $P>P_{c r}$

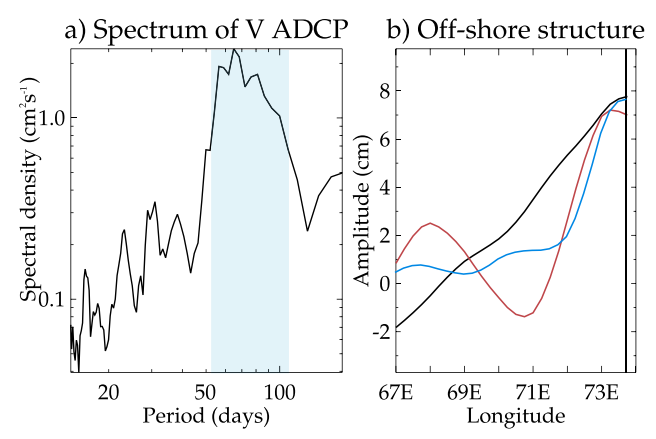

Figure 2. (a) Power spectrum of the ADCP alongshore current at $50 \mathrm{~m}$. Shading highlights the 55-110 day band. (b) Intraseasonal (55-110 day, red curve and 30-60 day, blue curve) and seasonal (110 day low-passed, black curve) typical offshore sea-level structure, computed as the covariance between the filtered sea level and its normalized value at the coast (indicated by the vertical black line). The 55-110 day (30-60 day) structure function has been multiplied by 3.5 (5) in order to be more easily compared with the stronger signal at seasonal scale. 


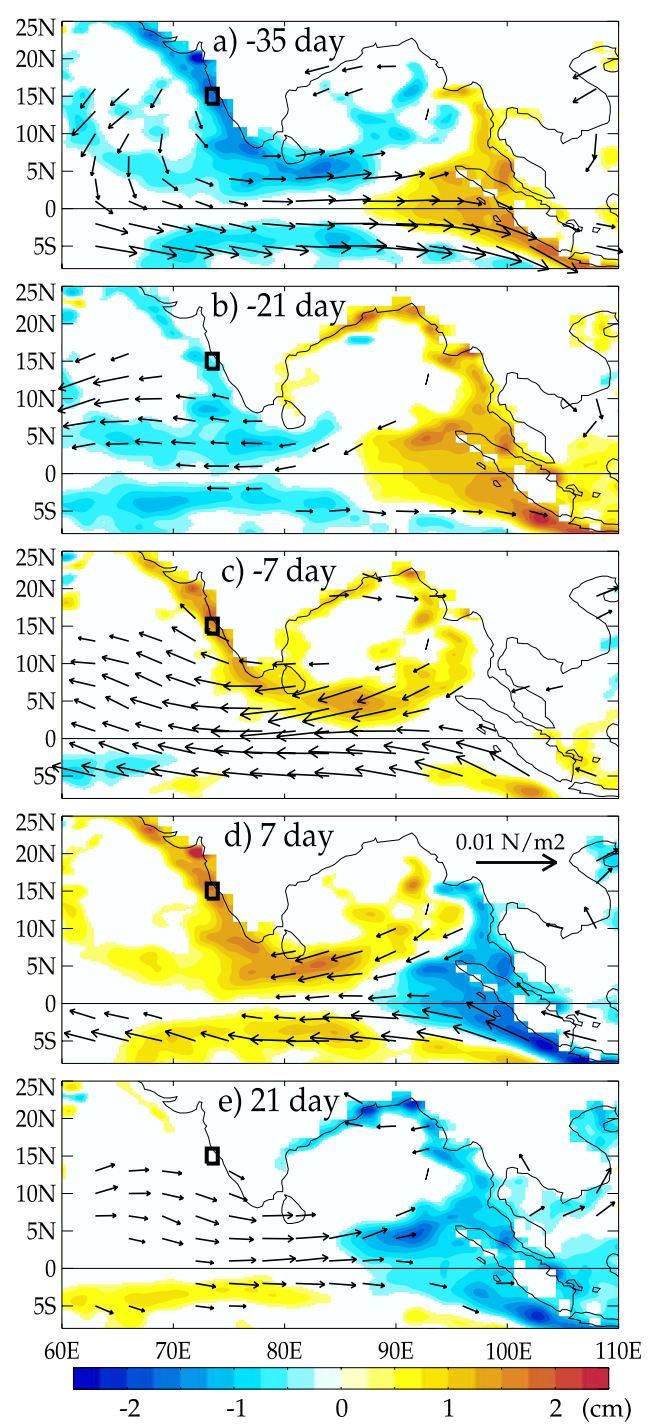

Figure 3. Regression of 55-110 day filtered sea level $(\mathrm{cm})$ and ERS-Quickscat winds $\left(\mathrm{N} . \mathrm{m}^{-2}\right.$ ) to normalized 55110 day filtered sea level within the black box $\left(73^{\circ} \mathrm{E}\right.$ to $74^{\circ} \mathrm{E}$, $14^{\circ} \mathrm{N}$ to $16^{\circ} \mathrm{N}$ ). Patterns leading by (a) 35 day, (b) 21 day, (c) 7 day and lagging by (d) 7 day, (e) 21 day with respect to the intraseasonal sea level off Goa. The 35-day lag pattern is quite similar to the pattern shown in Figure $3 \mathrm{a}$ and has not been plotted. Values that are not significant at the $95 \%$ confidence level have been masked.

and hence are coastally trapped. Theoretically, they weaken offshore exponentially with an e-folding scale of the Rossby radius of deformation (e.g., see Section 10.4 of Gill [1982]), which is $\sim 60 \mathrm{~km}$ for the first baroclinic mode at this location [Chelton et al., 1998]. At longer periods (e.g., the seasonal cycle), coastal sea-level variations radiate offshore as Rossby waves, and hence sea level changes much more gradually offshore.

[13] To verify these predictions, Figure $2 b$ shows the typical offshore structure of sea level for three frequency bands: the 30-60 day and 55-110 day band-passed anomalies of sea level with respect to the mean seasonal cycle, and the 110-day, low-passed, total sea level (including the mean seasonal cycle). At high frequencies (30-60 day), the sea- level signal decreases sharply away from the coast, suggesting that the sea-level signal in this frequency band is fully coastally trapped at this latitude. For the 55-110 day band of relevance here, there is still a very significant coastal trapping. Oscillations away from the coast in Figure 2b, however, suggest some offshore propagation similar to that given by Shankar and Shetye [1997, Figure 8], consistent with the linear theory prediction that the critical period is $\sim 90$ day at this latitude. In contrast with the coastal trapping at intraseasonal timescales, the offshore signal at lower frequencies decreases much more gradually, as illustrated by Shankar and Shetye [1997, Figure 6]. Since the alongshore current is in geostrophic balance with the across-shore pressure gradient, current variations associated with intraseasonal timescales are much stronger than they are for seasonal timescales, accounting for the weakness of the latter in the mooring record. Furthermore, for a theoretical Kelvin wave the alongshore current $v$ and sea level $\eta$ are linked by the expression $v=\left(\mathrm{g} / c_{1}\right) \eta$, where $\mathrm{g}$ is the acceleration of gravity. Using the value of $c_{1}$ noted above, this relation becomes $v=3.8 \eta$, which is approximately verified for the 55-110 day band in Figure $1 \mathrm{~b}$.

[14] To investigate the origins of the sea-level variations off Goa, Figure 3 presents the typical wind stress and sealevel patterns associated with them. The intraseasonal variability along the west coast of India is part of a basinscale phenomenon. Similar maps are obtained (with just a shift of the lags) when the regression is done with sea level in one of the other regions of strong variability associated with this basin-wide signal (e.g., the eastern equatorial Indian Ocean, west coast of Thailand, or southern tip of India, etc.).

[15] Figure 3a shows a westerly wind anomaly over the central and eastern equatorial Indian Ocean, leading the sealevel signal off Goa by 35 days. This westerly wind anomaly forces an upwelling equatorial Rossby-wave response with clear patches of negative sea-level anomaly at $5^{\circ} \mathrm{N}$ and $5^{\circ} \mathrm{S}$ between $70^{\circ} \mathrm{E}$ and $90^{\circ} \mathrm{E}$. It also induces a downwelling equatorial Kelvin wave that has already reached the Indonesian coast in Figure 3a. Part of the impinging energy is reflected as a downwelling equatorial Rossby wave, which propagates back to the central Indian ocean (Figures $3 b-3 d$ ). Another part propagates into the Bay of Bengal as a downwelling coastal Kelvin wave (Figure $3 b$ ). The characteristic (wedge) shape of the signal in the eastern Indian Ocean in Figures $3 b-3 d$ is consistent with the properties that reflected Rossby waves propagate more slowly away from the equator, and that there is coastal trapping beyond some critical latitude (here $\sim 15^{\circ} \mathrm{N}$ ). The coastal downwelling Kelvin wave propagates through the Andaman Sea and then all around the Bay of Bengal with progressively attenuated amplitude (Figure $3 \mathrm{~b}$ ). It meets the reflected equatorial Rossby wave at the tip of Sri Lanka (Figure 3c).

[16] In the meantime, the equatorial wind has shifted from westerlies (Figure 3a) to easterlies (Figures 3b-3d), reinforcing the downwelling reflected Rossby-wave signal in the central and western ocean (Figures 3c and 3d). The resulting positive sea-level anomaly generated at the southern tip of India propagates northward along the west coast of India as a downwelling coastal Kelvin wave (Figure 3c). The easterly wind anomaly along the equator excites 
upwelling, equatorial Kelvin waves, which progressively decrease sea level near Sumatra (Figures $3 b-3 d$ ). The wind then switches back to westerlies (Figure 3e) and at lag +35 day (not shown), the wind and sea-level anomalies are quite similar to those seen in Figure 3a.

[17] Despite having been constructed on the basis of a sea-level index, the wind patterns seen in Figure 3 share a lot of common features to MJO composites shown for both winter and summer seasons by Wheeler and Hendon [2004, Figures 8 and 9]. These features include the predominance of zonal wind signals along the equator, the eastward propagation of the wind signal (e.g., Figures $3 b-3 d$ ), and the timescale (here $\sim 70-90$ days, while the MJO is energetic between roughly 30 and 80 days). The equatorial wind signature of the MJO thus largely drives the basinscale intraseasonal response.

\section{Discussion}

[18] Surface wind associated with the MJO has most energetic variations at the 30-80 day timescale [e.g., Wheeler and Hendon, 2004]. We have shown that the sealevel response forced by MJO winds propagates northward into the Bay of Bengal and along the west coast of India as coastal Kelvin waves. Although intraseasonal sea-level signals are significantly smaller than the seasonal ones (the amplitude off Goa is $\sim 2.5 \mathrm{~cm}$ in the 55-110 day band and $\sim 10 \mathrm{~cm}$ for seasonal harmonics), they dominate the current fluctuations on western continental margins, as illustrated by surface current observations at $15^{\circ} \mathrm{N}$. This difference arises because intraseasonal signals are trapped at the coast north of some critical latitude, whereas seasonal signals radiate westward as Rossby waves. As a result, the across-shore sea-level gradient is much larger at intraseasonal timescales, and hence the geostrophic alongshore coastal currents are much stronger. Alongshore current fluctuations at $15^{\circ} \mathrm{N}$ are reasonably approximated by intraseasonally filtered sea-level anomalies, a proxy for the intraseasonal coastal Kelvin wave amplitude.

[19] While this paper presents a clear basin-scale connection between the equatorial waveguide and coastal currents in the Northern Indian Ocean at the intraseasonal timescale, there are several important issues that require further exploration. First, both intraseasonal and seasonal sea-level signals are trapped along the east coast of India, which likely explains why there are significant current variations at both seasonal and intraseasonal timescales there [Durand et al., 2009]. In contrast, our results suggest that currents are dominated by intraseasonal fluctuations over most of the west coast of India, except maybe near the southern tip of India where a more significant portion of intraseasonal variability can radiate away westward $\left(P_{c r} \sim\right.$ 60 day). Ship-drift estimates of currents should be interpreted with caution in this region, because they probably suffer from significant aliasing from intraseasonal frequencies. In short, the description of the WICC as a seasonally reversing current probably needs to be revised, and requires a more accurate quantification of its seasonal and intraseasonal components.

[20] Although the MJO is associated with most energetic fluctuations of equatorial zonal wind stress between 30 and 60 day, the basin-scale sea level seems to respond selec- tively at lower frequency [Han et al., 2001; Han, 2005]. This is also illustrated by results in this paper where timescales associated with currents off Goa (55-110 day), or with Figure 3 (70-90 day) are also longer than the dominant timescale of the MJO. A possible reason is that downward propagation of energy along the wave path at intraseasonal timescales [Nethery and Shankar, 2007] results in an amplitude decrease far from the forcing region at higher frequencies. Other possibilities are that the frequency shift is due to the resonant response of the equatorial Indian Ocean to wind forcing at 90 day [Han, 2005], or that it emerges as a "natural" timescale associated with reflection of intraseasonal Kelvin waves at the eastern boundary [Sengupta et al., 2007]. The detailed mechanisms explaining this frequency shift of the upper-ocean response in the northern Indian Ocean require further exploration.

[21] Third, the precise forcing mechanism of the intraseasonal Kelvin wave along the west coast of India needs to be ascertained. At the seasonal timescale, remote forcing from the Bay of Bengal is important for sea-level variations along the west coast of India [McCreary et al., 1993; Shankar and Shetye, 1997]. At intraseasonal timescales, this contribution is probably smaller, as suggested by Figures 3c and 3e and by the Nethery and Shankar [2007] theory that there is a significant loss of energy to the abyss along the wave path in the intraseasonal frequency range. It is also likely that alongshore winds between $15^{\circ} \mathrm{N}$ and the tip of India and Sri Lanka play an important role, as proposed by Shetye et al. [2008]. Furthermore, although they share many features, the summer intraseasonal variability and MJO variability are not identical [e.g., Goswami, 2005]. The latter seems to be more efficient in forcing a response in the oceanic equatorial waveguide in summer [Senan et al., 2003]. The seasonality of the intraseasonal response of the Indian Ocean and the relative roles of the MJO and summer ISV need to be ascertained. Such questions can be addressed more easily within a modeling framework.

[22] We finish by noting a practical application for these results. There are many reasons to doubt the validity of satellite sea-level products close to the shore (inaccurate tidal corrections, contamination of land values, etc.). We have shown, however, that intraseasonally-filtered sea level at $15^{\circ} \mathrm{N}$ on the west coast of India do provide a reasonable approximation of surface current variations, providing a possible tool for near real-time monitoring. The theoretical framework proposed here suggests that this approach should be valid along other west coasts elsewhere, such as those along Myanmar, America, and Africa.

[23] Acknowledgments. The lead author worked on this paper while visiting the National Institute of Oceanography. Authors from NIO thank INCOIS/MoES and CSIR for financial support. J. McCreary acknowledges support from the Frontier Research Center for Global Change through its sponsorship of the International Pacific Research Center. The altimeter products were produced by Ssalto/Duacs and distributed by AVISO with support from CNES. The wind stress data were obtained from CERSAT, at IFREMER, Plouzané (France). This manuscript is NIO publication 4552, SOEST contribution 7765, and IPRC contribution 617.

\section{References}

Chelton, D. B., R. A. DeSzoeke, M. Schlax, K. El Naggar, and N. Siwertz (1998), Geographical variability of the first baroclinic Rossby radius of deformation, J. Phys. Oceanogr., 28, 433-460, doi:10.1175/15200485(1998)028<0433:GVOTFB >2.0.CO;2. 
Durand, F., D. Shankar, F. Birol, and S. S. C. Shenoi (2009), Spatiotemporal structure of the East India Coastal Current from satellite altimetry, J. Geophys. Res., 114, C02013, doi:10.1029/2008JC004807.

Gill, A. E. (1982), Atmosphere-Ocean Dynamics, 662 pp., Academic, New York.

Goswami, B. N. (2005), South Asian monsoon, in Intraseasonal Variability in the Atmosphere-Ocean Climate System, edited by W. K. M. Lau and D. E. Waliser, pp. 19-55, Springer, Berlin.

Han, W. (2005), Origins and dynamics of the 90-day and 30-60-day variations in the equatorial Indian Ocean, J. Phys. Oceanogr., 35, 708-728, doi:10.1175/JPO2725.1.

Han, W., D. M. Lawrence, and P. J. Webster (2001), Dynamical response of equatorial Indian Ocean to intraseasonal winds: Zonal flow, Geophys. Res. Lett., 28, 4215-4218, doi:10.1029/2001GL013701.

Masumoto, Y., H. Hase, Y. Kuroda, H. Matsuura, and K. Takeuchi (2005), Intraseasonal variability in the upper layer currents observed in the eastern equatorial Indian Ocean, Geophys. Res. Lett., 32, L02607, doi:10.1029/2004GL021896.

McCreary, J. P., Jr., P. K. Kundu, and R. L. Molinari (1993), A numerical investigation of dynamics, thermodynamics and mixed layer processes in the Indian Ocean, Prog. Oceanogr., 31, 181-244, doi:10.1016/00796611(93)90002-U.

McCreary, J. P., W. Han, D. Shankar, and S. R. Shetye (1996), Dynamics of the East India Coastal Current: 2. Numerical solutions, J. Geophys. Res., 101, 13,993-14,010, doi:10.1029/96JC00560.

Nethery, D., and D. Shankar (2007), Vertical propagation of baroclinic Kelvin waves along the west coast of India, J. Earth Syst. Sci., 116, 331-339, doi:10.1007/s12040-007-0030-6.

Reppin, J., F. A. Schott, J. Fischer, and D. Quadfasel (1999), Equatorial currents and transports in the upper central Indian Ocean: Annual cycle and interannual variability, J. Geophys. Res., 104, 15,495-15,514, doi:10.1029/1999JC900093.

Schott, F., and J. P. McCreary (2001), The monsoon circulation of the Indian Ocean, Prog. Oceanogr., 51, 1-123, doi:10.1016/S00796611(01)00083-0.

Senan, R., D. Sengupta, and B. N. Goswami (2003), Intraseasonal “monsoon jets" in the equatorial Indian Ocean, Geophys. Res. Lett., 30(14), 1750, doi:10.1029/2003GL017583.
Sengupta, D., R. Senan, and B. N. Goswami (2001), Origin of intraseasonal variability of circulation in the tropical central Indian Ocean, Geophys. Res. Lett., 28, 1267-1270, doi:10.1029/2000GL012251.

Sengupta, D., R. Senan, B. N. Goswami, and J. Vialard (2007), Intraseasonal variability of equatorial Indian Ocean zonal currents, J. Clim., 20, 3036-3055, doi:10.1175/JCLI4166.1.

Shankar, D., and S. R. Shetye (1997), On the dynamics of the Lakshadweep high and low in the southeastern Arabian Sea, J. Geophys. Res., 102, 12,551-12,562, doi:10.1029/97JC00465.

Shenoi, S. S. C., P. K. Saji, and A. M. Almeida (1999), Near-surface circulation and kinetic energy in the tropical Indian Ocean derived from Lagrangian drifters, J. Mar. Res., 57, 885-907, doi:10.1357/ 002224099321514088 .

Shetye, S. R., I. Suresh, D. Shankar, D. Sundar, S. Jayakumar, P. Mehra, R. G. Prabhudesai, and P. S. Pednekar (2008), Observational evidence for remote forcing of the West India Coastal Current, J. Geophys. Res., 113, C11001, doi:10.1029/2008JC004874.

Wheeler, M. C., and H. H. Hendon (2004), An all-season real-time multivariate MJO index: Development of an index for monitoring and prediction, Mon. Weather Rev., 132, 1917-1932, doi:10.1175/15200493(2004)132<1917:AARMMI>2.0.CO;2.

Zhang, C. (2005), Madden-Julian Oscillation, Rev. Geophys., 43, RG2003, doi:10.1029/2004RG000158.

S. S. C. Shenoi, Indian National Centre for Ocean Information Services, P.B. No. 21, IDA Jeedimetla P.O., Hyderabad 500 055, India.

F. Durand, Laboratoire d'Etudes en Géophysique et Oceanographie Spatiales, IRD, 14 Avenue Edouard Belin, F-31400 Toulouse CEDEX, France.

V. Fernando, D. Shankar, and S. R. Shetye, Physical Oceanography Division, National Institute of Oceanography, CSIR, Dona Paula, Goa 403 004, India.

J. P. McCreary, International Pacific Research Centre, University of Hawaii, POST Building, Room 401, 1680 East West Road, Honolulu, HI 96822, USA.

J. Vialard, LOCEAN, IRD, Université Pierre et Marie Curie, Case 100, 4, place Jussieu, F-75232 Paris CEDEX 05, France. (jv@locean-ipsl.upmc.fr) 